\title{
Compounding from Bulk Ingredient
}

National Cancer Institute

\section{Source}

National Cancer Institute. Compounding from Bulk Ingredient. NCI Thesaurus. Code C112092.

A compounder produces a drug with bulk ing redients. 